\title{
Wskaźnik niepełnosprawności głosowej - efektywność i korelacja pomiędzy cechami fizycznymi, funkcjonalnymi oraz emocjonalnymi a zaburzeniami głosu
}

\section{Voice Handicap Index - efficiency and correlation between physical, functional and emotional aspects and voice disorders}

\author{
Marcin Scech \\ Studium Doktoranckie Wydziału Nauk o Zdrowiu Pomorskiego Uniwersytetu Medycznego w Szczecinie \\ ul. Żołnierska 54, 71-210 Szczecin \\ Kierownik: prof. dr hab. n. med. Maria Laszczyńska
}

\begin{abstract}
Voice disorders are a very common medical problem among people whose occupation requires overusing their voice as a working tool. The lack of correct voice projection and phonation training courses is the reason why voice disorders are commonly found throughout society. In order to identify the reasons causing voice disorders, the Voice Handicap Index (VHI) may
\end{abstract}

be used. As an instrument of iterative testing, the VHI allows not only self-assessment of someone's voice, but it is also a very helpful research tool during verification of the effects of voice rehabilitation.

Keywords: voice, disorder, Voice Handicap Index, rehabilitation, dysphonia.

\section{STRESZCZENIE}

Zaburzenia głosu są powszechnym zjawiskiem wśród osób pracujących w środowiskach narażonych na nadmierne używanie mowy jako narzędzia pracy. Brak wcześniejszego szkolenia z zakresu prawidłowej impostacji oraz fonacji powoduje, że kłopoty z głosem są obecne w dużej części społeczeństwa. W odpowiednim ropoznaniu powodów powstawania zaburzeń głosu pomaga współczynnik niepełnosprawności głosowej czyli Voice Handicap Index (VHI). Jako narzędzie wielokrotnie sprawdzone, pozwala nie tylko na samoocenę własnego głosu, ale również jest pomocne podczas weryfikacji efektów rehabilitacji głosu. Słowa kluczowe: głos, zaburzenia, Voice Handicap Index, rehabilitacja, dysfonia.
Głos ludzki, postrzegany przez lata jako środek do komunikacji lub wyrażania emocji, od pewnego czasu pozostaje w dużym zainteresowaniu specjalistów, którzy próbują go analizować również jako narzędzie pracy. Pośród wielu profesji, w których jest on podstawową umiejętnością weryfikującą przydatność do wykonywanego zawodu, są spikerzy telewizyjni i radiowi, aktorzy, śpiewacy, nauczyciele czy księża. Najwięcej miejsca $\mathrm{w}$ badaniach poświęcono zaburzeniom głosu występującym wśród nauczycieli. Powodem może być fakt, że jest to grupa zawodowa mocno narażona na obciążenia wynikające z funkcjonowania w ciągłym stresie, a jednocześnie niebędąca odpowiednio przygotowana do pracy głosem [1]. Pozostałe grupy zawodowe, z racji nauki prawidłowej impostacji oraz fonacji w trakcie procesu edukacyjnego (śpiewacy, dziennikarze i aktorzy mają obowiązkowe zajęcia z emisji głosu w trakcie nauki), wydają się być mniej narażone na zaburzenia głosu. Nie do końca jednak jest to zgodne z rzeczywistością, ponieważ czysty, brzmiący głos to nie tylko efekt poprawnego posługiwania się narządem głosu, ale również szereg czynników zewnętrznych i wewnętrznych mających wpływ na jego jakość. Dlatego też niepełnosprawność głosowa to problem bardziej kompleksowy.

Światowa Organizacja Zdrowia określa niepełnosprawność jako społeczne, ekonomiczne i środowiskowe ograniczenia wynikające z niemożności lub braku możliwości wykonania codziennych obowiązków [2]. Mając to na uwadze, w obecnych czasach równie ważnym czynnikiem do oceny stanu zdrowia pacjenta jest jego subiektywne odczucie. Przy rozwoju nowych zastosowań technicznych oraz metod laboratoryjnych badania jakości głosu coraz częściej stosuje się testy, w których to pacjent dokonuje samooceny swojego głosu. Spośród wielu dostępnych, najczęściej używanym jest wskaźnik niepełnosprawności głosowej - Voice Handicap Index (VHI) [3, 4, 5].

Wskaźnik niepełnosprawności głosowej (załącznik nr 1) został utworzony przez Jacobson i wsp. w 1997 r. [6]. Początkowo był to zestaw zawierający 85 części. W trakcie trwania walidacji został ograniczony do 65 , aby w ostatecznej, obowiązującej obecnie formie, zawierać 30 pytań, które mają na celu 
zbadanie jakości głosu pacjenta. Pytania zawarte w VHI zostały podzielone na 3 podgrupy, w których występowanie zaburzeń głosu warunkowane jest aspektami fizycznymi, emocjonalnymi oraz funkcjonalnymi. Każda z części zawiera 10 pytań lub opisów sytuacji. Wypełniając osobiście ankietę, każdy z pacjentów zobowiązany jest ocenić subiektywne odczucia. Obowiązuje 5-stopniowa skala od 0 - nigdy, poprzez 1 - prawie nigdy, 2 - czasami, 3 - prawie zawsze, do 4 - zawsze. Oceniając każdą z części osobno, a następnie sumując punkty wszystkich 3, w rezultacie otrzymuje się od minimalnej sumy punktów, czyli 0, do maksymalnej, czyli 120. Im gorzej pacjent będzie oceniał swoją niepełnosprawność głosową, tym większa będzie liczba punktów w efekcie końcowym.

Oryginalnie VHI zostało stworzone na potrzeby specjalistów amerykańskich. Ponieważ zostało zredagowane w języku angielskim, wskaźnik ten mógł być swobodnie wykorzystywany tylko w tych w krajach, gdzie język angielski był językiem urzędowym. Szereg przeprowadzonych badań, w których z sukcesem wykorzystano wskaźnik niepełnosprawności głosowej [7], zachęcił naukowców do zastosowania VHI na większej liczbie pacjentów, co z kolei wiązało się z koniecznością przetłumaczenia go na wiele innych języków. Teraz wskaźnikiem tym można posługiwać się np. w języku niemieckim [8], chińskim [9], portugalskim [10] czy polskim (załącznik nr 2) [11] oraz wielu innych.

Dostępność w wielu językach nie tylko daje możliwość szerokiego zastosowania VHI, ale jednocześnie jest dowodem na jego skuteczność. Potwierdzeniem tego są zrealizowane badania z wykorzystaniem VHI. Jedno z takich badań prowadzone było w Polsce na 45 nauczycielkach z czynnościowymi zaburzeniami głosu, które oceniły swoje problemy z głosem używając VHI zarówno przed leczeniem foniatrycznym, jak i po. Kobiety podzielono na dwie grupy - grupa I - 29 osób oraz grupa II - 16 osób. Grupa I przeszła rehabilitację głosu, natomiast grupa II jedynie szkolenie z zakresu higieny głosu. Użycie testu w badaniu pozwoliło określić poprawę wszystkich aspektów (fizycznych, funkcjonalnych i emocjonalnych) w grupie I, podczas gdy w grupie II dotyczyła ona tylko podskali fizycznej. Jest to dowodem na skuteczność monitorowania dysfonii u nauczycieli za pomocą VHI [12].

Podobnie wyglądało to podczas badania pacjentów z porażeniem fałdów głosowych. Przebadano wówczas 90 osób, z czego 25 chorych oraz 65 zdrowych, u których krtań funkcjonowała prawidłowo. Wykazano, że w porównaniu z grupą kontrolną, pacjenci z dysfonią porażenną mieli dużo gorsze wyniki testu VHI. Aż 68\% pacjentów, którzy byli zdiagnozowani z porażeniem fałdów głosowych, przejawiało średnią niesprawność głosu, natomiast $24 \%$ badanych dużą niesprawność. Wyniki osób z grupy kontrolnej plasowały się w najniższym przedziale, co oznaczało, że nie odczuwali oni znaczących dolegliwości związanych z narządem głosu. To pozwoliło uznać wskaźnik VHI jako wartościowy w przypadku samooceny głosu wśród pacjentów z porażeniami fałdów głosowych [13].

Voice Handicap Index znalazł również zastosowanie przy badaniu pacjentów z umiarkowaną do ciężkiej obustronną czuciowo-nerwową utratą słuchu [14]. Przebadano 76 dorosłych pacjentów, z czego 36 osób z utratą słuchu oraz kolejnych 36 zdrowych. W rezultacie znaleziono znaczące różnice pomiędzy tymi grupami we wszystkich aspektach VHI (fizycznych, funcjonalnych i emocjonalnych).

Kolejnym z wielu przykładów potwierdzających skuteczność VHI może być badanie, do którego autorzy zmodyfikowali podstawową wersję wskaźnika niepełnosprawności głosowej na potrzeby badania dzieci. W ten sposób powstał pVHI, czyli Pediatric Voice Handicap Index. Badanie przeprowadzono w Turcji, a skierowane było do 151 rodziców, których 111 dzieci nie zgłaszało problemów z głosem, a 40 było dziećmi dysfonicznymi. Udowodniono, że turecka wersja pVHI jest skuteczną metodą, którą rodzice mogą stosować, aby sprawdzić problemy z głosem swoich dzieci [15].

Śpiewacy, niezależnie od rodzaju wykonywanej muzyki, to specyficzna grupa zawodowa, zwłaszcza jeśli spojrzy się na nią z perspektywy zaburzeń głosu [16, 17]. Dlatego też ta grupa doczekała się zmodyfikowanej wersji wskaźnika niepełnosprawności głosowej - Singing Voice Handicap Index (załącznik 3) [18].

Składa się on z 36 pytań, które również rzutują na aspekty fizyczne, funkcjonalne oraz emocjonalne badanego, ale treść pytań skupiona jest na śpiewaniu. W trakcie badań tej grupy zawodowej okazało się, że specyficzne oczekiwania śpiewaków odnośnie jakości dźwięku zachęciły do szerszego spojrzenia na ten problem, w skutek czego pojawiły się takie modulacje VHI, jak Classical Voice Handicap Index [19] i Modern Singing Handicap Index [20]. Jednak to właśnie VHI, czasami w wersji skróconej do 10 pytań - VHI-10 [21], jest wykorzystywany $\mathrm{w}$ badaniach najczęściej, a co za tym idzie, ma największe potwierdzenie skuteczności. Badanie z wykorzystaniem obu wersji VHI przeprowadzono w Portugalii na liczbie 118 śpiewaków, których podzielono na rodzaj wykonywanej muzyki (klasyczna i popularna) oraz, wewnątrz obu grup, na zgłaszających problem ze śpiewem i tych, którzy nie odczuwali żadnych kłopotów podczas śpiewania. Obie wersje VHI okazały się być bardzo pomocne w ocenie wszystkich trzech aspektów samooceny. Zaobserwowane różnice pomiędzy śpiewakami pozwalają sądzić, że rodzaj wykonywanej muzyki ma różny wpływ na postrzeganie zaburzeń głosowych przez jej wykonawców [22].

Weryfikowalność VHI oraz jego niezawodność przyczyniły się do stworzenia oprogramowania, które w formie open-source udostępnia darmową aplikację zawierającą VHI przetłumaczone na wiele języków [23].

\section{WNIOSKI}

W artykule wykazano przydatność stosowania wskaźnika niepełnosprawności głosowej jako narzędzia wiarygodnego i powszechnie dostępnego. Voice Handicap Index jest prostą metodą oceny głosu w skalach subiektywnych, która powinna być wzięta pod uwagę w kompleksowym podejściu do badania foniatrycznego lub laryngologicznego. 


\section{VOICE HANDICAP INDEX}

Name:

Date:

These are statements that many people have used to describe their voices and the effects of their voices on their lives. Circle the response that indicates how frequently you have the same experience.
0-never
1-almost never
2-sometimes
3-almost always
4-always

Part I-F

\begin{tabular}{|c|c|c|c|c|c|}
\hline My voice makes it difficult for people to hear me. & 0 & 1 & 2 & 3 & 4 \\
\hline People have difficulty understanding me in a noisy room. & 0 & 1 & 2 & 3 & 4 \\
\hline My family has difficulty hearing me when I call them throughout the house. & 0 & 1 & 2 & 3 & 4 \\
\hline I use the phone less often than I would like to. & 0 & 1 & 2 & 3 & 4 \\
\hline I tend to avoid groups of people because of my voice. & 0 & 1 & 2 & 3 & 4 \\
\hline I speak with friends, neighbors, or relatives less often because of my voice. & 0 & 1 & 2 & 3 & 4 \\
\hline People ask me to repeat myself when speaking face-to-face. & 0 & 1 & 2 & 3 & 4 \\
\hline My voice difficulties restrict my personal and social life. & 0 & 1 & 2 & 3 & 4 \\
\hline I feel left out of conversations because of my voice. & 0 & 1 & 2 & 3 & 4 \\
\hline My voice problem causes me to lose income. & 0 & 1 & 2 & 3 & 4 \\
\hline
\end{tabular}

SUBTOTAL

\section{Part II-P}

\begin{tabular}{|c|c|c|c|c|c|}
\hline I run out of air when I talk. & 0 & 1 & 2 & 3 & 4 \\
\hline The sound of my voice varies throughout the day. & 0 & 1 & 2 & 3 & 4 \\
\hline People ask, "What's wrong with your voice?" & 0 & 1 & 2 & 3 & 4 \\
\hline My voice sounds creaky and dry. & 0 & 1 & 2 & 3 & 4 \\
\hline I feel as though I have to strain to produce voice. & 0 & 1 & 2 & 3 & 4 \\
\hline The clarity of my voice is unpredictable. & 0 & 1 & 2 & 3 & 4 \\
\hline I try to change my voice to sound different. & 0 & 1 & 2 & 3 & 4 \\
\hline I use a great deal of effort to speak. & 0 & 1 & 2 & 3 & 4 \\
\hline My voice is worse in the evening. & 0 & 1 & 2 & 3 & 4 \\
\hline My voice "gives out" on me in the middle of speaking. & 0 & 1 & 2 & 3 & 4 \\
\hline
\end{tabular}

SUBTOTAL

\section{Part III-E}

\begin{tabular}{|c|c|c|c|c|c|}
\hline I am tense when talking to others because of my voice. & 0 & 1 & 2 & 3 & 4 \\
\hline People seem irritated with my voice. & 0 & 1 & 2 & 3 & 4 \\
\hline I find other people don't understand my voice problem. & 0 & 1 & 2 & 3 & 4 \\
\hline My voice problem upsets me. & 0 & 1 & 2 & 3 & 4 \\
\hline I am less outgoing because of my voice problem. & 0 & 1 & 2 & 3 & 4 \\
\hline My voice makes me feels handicapped. & 0 & 1 & 2 & 3 & 4 \\
\hline I feel annoyed when people ask me to repeat. & 0 & 1 & 2 & 3 & 4 \\
\hline I feel embarrassed when people ask me to repeat. & 0 & 1 & 2 & 3 & 4 \\
\hline My voice makes me feel incompetent. & 0 & 1 & 2 & 3 & 4 \\
\hline I am ashamed of my voice problem. & 0 & 1 & 2 & 3 & 4 \\
\hline
\end{tabular}

I am ashamed of my voice problem.

TOTAL

The Voice Handicap Index (VHI): Development and Validation

Barbara H. Jacobson, Alex Johnson, Cynthia Grywalski, Alice Silbergleit, Gary Jaconsen, Michael S. Benninger 
ZAŁĄCZNIK NR 2.

WSKAŹNIK NIEPEŁNOSPRAWNOŚCI GŁOSOWEJ - VOICE HANDICAP INDEX W WERSJI POLSKIEJ (PrusZewicZ i WSP. [11])

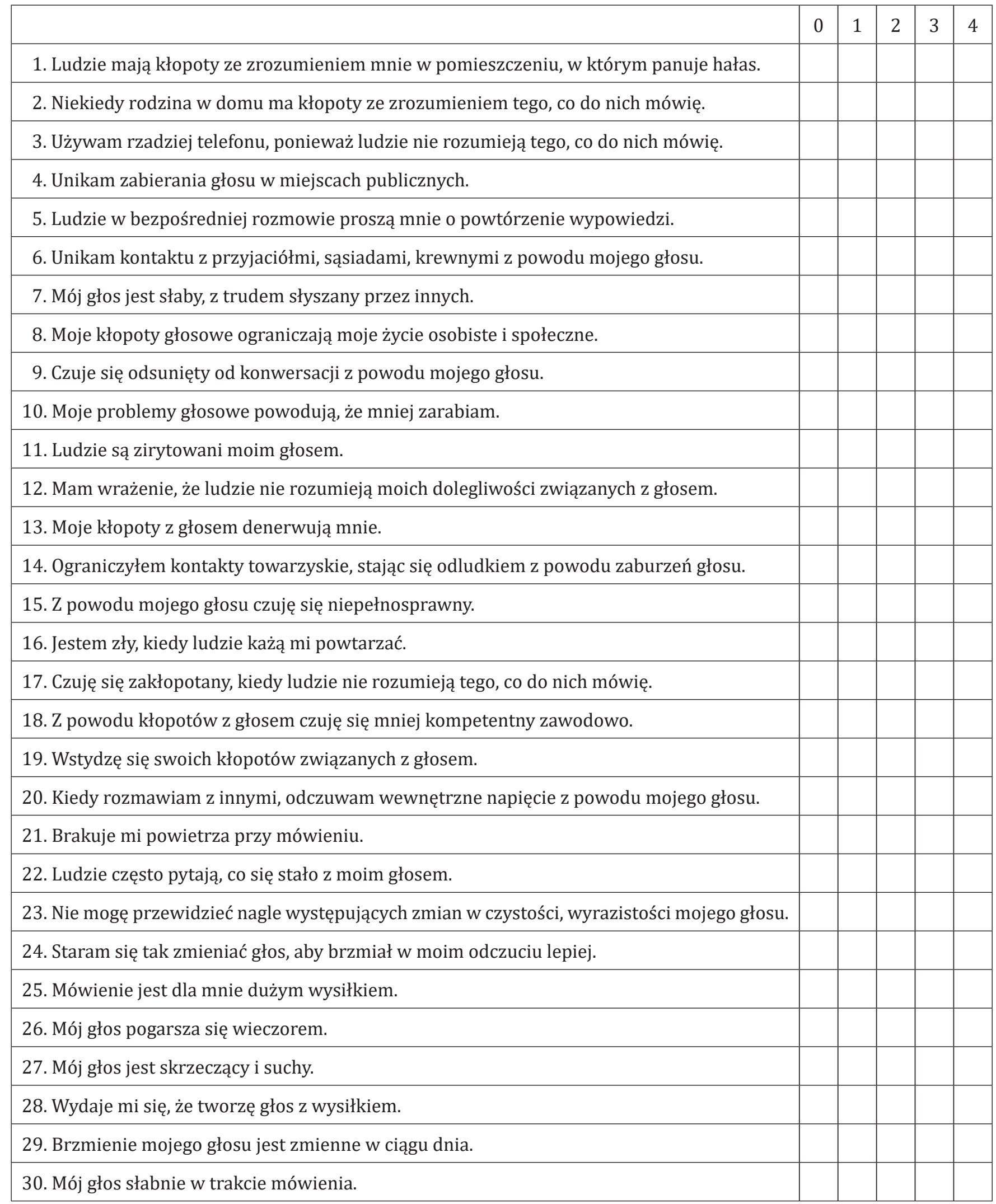

Punkty: 0 - nigdy; 1 - prawie nigdy; 2 - czasem; 3 - prawie zawsze; 4 - zawsze. 


\section{ZAŁĄCZNIK NR 3.}

\section{SINGING VOICE HANDICAP INDEX}

\section{/144 total}

\section{Singing Voice Handicap Index}

Circle the word that matches how serious you feel your singing voice problem is overall:
No Problem
Mild Problem
Moderate Problem
Severe Problem

Circle the word that matches how you feel your singing voice is today:
No Problem
Mild Problem
Moderate Problem
Severe Problem

Percent of normal: From 0 to $100 \%$, with $0 \%$ being no voice and $100 \%$ being your normal voice, rate your singing voice today: $\%$

Instructions: These are statements that many people have used to describe their singing and the effects of their singing on their lives. Check the response that indicates how frequently you have had the same experience in the last month.

\begin{tabular}{|c|c|c|c|c|c|c|}
\hline & & Never & $\begin{array}{c}\text { Almost } \\
\text { Never }\end{array}$ & Sometimes & $\begin{array}{l}\text { Almost } \\
\text { Always }\end{array}$ & Always \\
\hline F1 & It takes a lot of effort to sing. & & & & & \\
\hline $\mathrm{P} 2$ & My voice cracks and breaks. & & & & & \\
\hline F3 & I am frustrated by my singing. & & & & & \\
\hline P4 & People ask "What is wrong with your voice?" when I sing. & & & & & \\
\hline F5 & My ability to sing varies day to day. & & & & & \\
\hline F6 & My voice "gives out" on me while I am singing. & & & & & \\
\hline E7 & My singing voice upsets me. & & & & & \\
\hline F8 & My singing problems make me not want to sing/perform. & & & & & \\
\hline E9 & I am embarrassed by my singing. & & & & & \\
\hline P10 & I am unable to use my "high voice." & & & & & \\
\hline F11 & I get nervous before I sing because of my singing problems. & & & & & \\
\hline F12 & My speaking voice is not normal. & & & & & \\
\hline P13 & My throat is dry when I sing. & & & & & \\
\hline $\mathrm{P} 14$ & I've had to eliminate certain songs from my singing/performances. & & & & & \\
\hline E15 & I have no confidence in my singing voice. & & & & & \\
\hline F16 & My singing voice is never normal. & & & & & \\
\hline P17 & I have trouble making my voice do what I want it to. & & & & & \\
\hline P18 & I have to "push it" to produce my voice when singing. & & & & & \\
\hline F19 & I have trouble controlling the breathiness in my voice. & & & & & \\
\hline $\mathrm{P} 20$ & I have trouble controlling the raspiness in my voice. & & & & & \\
\hline $\mathrm{P} 21$ & I have trouble singing loudly. & & & & & \\
\hline
\end{tabular}




\begin{tabular}{|c|c|c|c|c|c|c|}
\hline & & Never & $\begin{array}{l}\text { Almost } \\
\text { Never }\end{array}$ & Sometimes & $\begin{array}{l}\text { Almost } \\
\text { Always }\end{array}$ & Always \\
\hline F22 & I have difficulty staying on pitch when I sing. & & & & & \\
\hline E23 & I feel anxious about my singing. & & & & & \\
\hline E24 & My singing sounds forced. & & & & & \\
\hline E25 & My speaking voice is hoarse after I sing. & & & & & \\
\hline P26 & My voice quality is inconsistent. & & & & & \\
\hline E27 & My singing voice makes it difficult for the audience to hear me. & & & & & \\
\hline E28 & My singing makes me feel handicapped. & & & & & \\
\hline E29 & My singing voice tires easily. & & & & & \\
\hline E30 & I feel pain, tickling, or choking when I sing. & & & & & \\
\hline E31 & I am unsure of what will come out when I sing. & & & & & \\
\hline E32 & I feel something is missing in my life because of my inability to sing. & & & & & \\
\hline E33 & I am worried my singing problems will cause me to lose money. & & & & & \\
\hline E34 & I feel left out of the music scene because of my voice. & & & & & \\
\hline E35 & My singing makes me feel incompetent. & & & & & \\
\hline E36 & $\begin{array}{l}\text { I have to cancel performances, singing engagements, rehearsals, or } \\
\text { practices because of my singing. }\end{array}$ & & & & & \\
\hline
\end{tabular}

For Clinician Use Only:

P Scale___ F Scale___ E Scale___ Total

Cohen, S.M., Jacobson, B.H., Garrett, C.G., Noordzij, J.P., Stewart, M.G., Attia, A., Ossoff, R.H., Cleveland, T.F. (2007) Creation and validation of the Singing Voice Handicap Index. Annals of Otology, Rhinology \& Laryngology, 116(6), 402-406 


\section{PIŚMIENNICTWO}

1. Śliwińska-Kowalska M, Niebudek-Bogusz E, Fiszer M, Łoś-Spychalska T, Kotyło P, Sznurowska-Przygocka B, et al. The prevalence and risk factors for occupational voice disorders in teachers. Folia Phoniatr Logop 2005;326:1-17.

2. Światowa Organizacja Zdrowia. Międzynarodowa Klasyfikacja Funkcjonowania Niepełnosprawności i Zdrowia (ICF). Genewa (Szwajcaria): Światowa Organizacja Zdrowia; 2009. p. 211-4.

3. Schindler A, Mozzanica F, Vedrody M, Maruzzi P, Ottaviani F. Correlation between th Voice Handicap Index and voice measurements in four groups of patients with dysphonia. Otolaryngol Head Neck Surg 2009;141(6): 762-9. doi: 10.1016/j.otohns.2009.08.021.

4. Morzaria S, Damrose EJ. A comparison of the VHI, VHI-10, and V-RQOL for measuring the effect of botox therapy in adductor spasmodic dysphonia. J Voice 2012;26(3):378-80.

5. Behlau M, Alves Dos Santos Lde M, Oliveira G. Cross-cultural adaptation and validation of the Voice Handicap Index into Brazilian Portuguese. J Voice 2011;25(3):354-9. doi: 10.1016/j.jvoice.2009.09.007. Epub 2010 May 1.

6. Jacobson BH, Johnson A, Grywalski C, Silbergleit A, Jacobson G, Benninger MS. The Voice Handicap Index (VHI): development and validation. Am J Speech Lang Pathol 1997;6:66-70.

7. Seifpanahi S, Jalaie S, Nikoo MR, Sobhani-Rad D. Translated Versions of Voice Handicap Index (VHI) - 30 across languages: a systematic review. Iran J Public Health 2015;44(4):458-69.

8. Nawka T, Wiesman U, Gonnermann U. Validierung des Voice Handicap Index (VHI) in der deutschen fassung. HNO 2003;51:921-9.

9. Hsiung MW, Lu P, Kang BH, Wang HW. Measurement and validation of the Voice Handicap Index in voice disordered patiens in Taiwan. J Laryngol Otol 2003;117:478-81.

10. Guimarães I, Abberton E. An investigation of the Voice Handicap Index with speakers of Portuguese: preliminary data. J Voice 2004;18:71-82.

11. Pruszewicz A, Obrębowski A, Wiskirska-Woźnica B, Wojnowski W. W sprawie kompleksowej oceny głosu - własna modyfikacja testu samooceny niesprawności głosu (Voice Handicap Idex). Otolaryngol Pol 2004;58: 547-9.

12. Niebudek-Bogusz E, Kuzańska A, Błoch P, Domańska M, Woźnicka E, Politański P, et al. Zastosowanie wskaźnika niepełnosprawności głosowej (Voice Handicap Index - VHI) w ocenie efektywności terapii głosu u nauczycieli. Med Pr 2007;58(6):501-9.

13. Niebudek-Bogusz E, Kuzańska A, Woźnicka E, Kopczyński J, Śliwińska-Kowalska M. Samoocena głosu za pomocą wskaźnika niepełnosprawności głosowej VHI u pacjentów z porażeniem fałdów głosowych. Otolaryngologia 2008;7(4):196-201.

14. Madeira FB, Tomita S. Voice Handicap Index evaluation in patiens with moderate to profound bilateral sensorineural hearing loss. Braz J Otorhinolaryngol 2010;76(1):59-70.

15. Özkan ET, Tüzüner A, Demirhan E, Topbas S. Reliability and validity of the Turkish pediatric voice handicap index. Int J Pediatr Otorhinolaryngopol 2015;79(5):680-4.

16. Rosen CA, Murry T. Voice Handicap Index in singers. J Voice 2000;1(3): 370-7.

17. Murry T, Zschommler A, Prokop J. Voice Handicap in singers. J. Voice 2009;23(3):376-9.

18. Cohen SM, Jacobson BH, Garrett CG, Noordzij JP, Stewart MG, Attia A, et al. Creation and validation of singing Voice Handicap Index. Ann Otol Rhinol Laryngol 2007;116(6):402-6.

19. Ávila ME, Oliveira G, Behlau M. Classical singing handicap index (CSHI) in erudite singers. Pro Fono 2010;22(3):221-6.

20. Moreti F, Rocha C, Borrego MCM, Behlau M. Voice handicap in singing: analysis of the Modern Singing Handicap Index - MSHI questionnaire. Rev Soc Bras Fonoaudiol 2011;16(2):146-51.

21. Rosen CA, Lee AS, Osborne J, Zullo T, Murry T. Development and validation of the voice handicap index-10. Laryngoscope 2004;114(9):1549-56.

22. Moreti F, Ávila ME, Rocha C, Borrego MC, Oliveira G, Behlau M. Influence of complaints and singing style in singers voice handicap. J Soc Bras Fonoaudiol 2012;24(3):296-300.

23. Herbst CT, Oh J, Vydrová J, Švec JG. Digital VHI - a freeware open-source software application to capture Voice Handicap Index and other questionnaire data in various languages. Logoped Phoniatr Vocol 2015;40(2):70-4. 